\title{
ARTICLE \\ Epidemiology \\ Midlife weight gain is a risk factor for obesity-related cancer
}

\author{
Susan Chadid ${ }^{1}$, Martha R. Singer ${ }^{1}$, Bernard E. Kreger ${ }^{2,3}$, M. Loring Bradlee ${ }^{1}$ and Lynn L. Moore ${ }^{1}$
}

BACKGROUND: Overweight and diabetes are known cancer risk factors. This study examines independent and combined effects of weight gain and metabolic dysfunction during middle-adult years on obesity-related cancer risk.

METHODS: Subjects $(n=3850)$ aged $45-69$ years at exams 3-5 in the Framingham Offspring Study were classified according to current and prior ( 14 years earlier) weight status, interim weight change and prevalent metabolic dysfunction. Cancer risk among subjects who were overweight at baseline and remained overweight, as well as those who became overweight during follow-up, was compared with risk among normal-weight individuals.

RESULTS: Gaining $\geq 0.45 \mathrm{~kg}$ ( $\geq 1.0$ pound)/year (vs. maintaining stable weight) over $\sim 14$ years increased cancer risk by $38 \%$ (95\% confidence interval (Cl), 1.09, 1.76); combined with metabolic dysfunction, weight gain increased cancer risk by $77 \%(95 \% \mathrm{Cl}, 1.21$, 2.59). Compared with non-overweight adults, men and women who became overweight during midlife had 2.18 -fold and 1.60 -fold increased cancer risks; those who were overweight from baseline had non-statistically significant 28 and $33 \%$ increased cancer risks, respectively, despite having a midlife body mass index that was $3.4 \mathrm{~kg} / \mathrm{m}^{2}$ higher than those who gained weight later.

CONCLUSION: Midlife weight gain was a strong cancer risk factor. This excess risk was somewhat stronger among those with concurrent metabolic dysfunction.

British Journal of Cancer (2018) 118:1665-1671; https://doi.org/10.1038/s41416-018-0106-x

\section{INTRODUCTION}

A number of studies have identified excess body fat as a modifiable risk factor for certain cancers; ${ }^{1}$ fewer studies have examined the effect of change in body weight (loss or gain) on obesity-related cancer risk. Amongst these, the relation between weight gain and the risk of postmenopausal breast cancer has been most commonly investigated. ${ }^{2-4}$ Other analyses from the Health Professional's Follow-up Study demonstrated that weight loss in men decreased the risk of colorectal, pancreatic and oesophageal cancers. ${ }^{5}$ A 2015 meta-analysis found a positive association between weight gain and colorectal cancer. ${ }^{6}$

In terms of overall obesity-related cancer, data from the Women's Health Initiative (WHI) showed that weight gain increased the risk of obesity-related cancer (a combination of ten cancers). ${ }^{7}$ Results from the Atherosclerosis Risk in Communities study also found that weight gain starting from early adulthood was associated with an increased risk of total cancer, particularly in women. ${ }^{8}$ A recent publication from the Nurses' Health Study and the Health Professional Follow-Up Study indicated a linear increase of obesity-related cancer associated with increasing weight gain for women. ${ }^{9}$

Components of the metabolic syndrome, such as elevated triglycerides and hypertension, have also been associated with increased cancer risk. ${ }^{10,11}$ The relation between adult weight gain and increased cancer risk may be attributable to intermediate effects on metabolic dysfunction or more direct pro-inflammatory effects of weight gain.

The primary objective of our analyses was to examine the independent and combined effects of adult weight change and accompanying metabolic dysfunction during the middle-adult years on risk of obesity-related cancer. A secondary aim was to examine whether subjects who were overweight or obese prior to middle age had a higher risk of obesity-related cancer than subjects who became overweight or obese later (during middleadult years). We explored whether these effects were modified by concurrent metabolic dysfunction.

\section{METHODS}

Study population

The Framingham Offspring Study includes the offspring of subjects participating in the original Framingham Heart Study, as well as their spouses. The Offspring Study began in 1971 with the enrolment of 5135 subjects. ${ }^{12}$ Exams 1 and 2 were 8 years apart, with the remaining exams occurring at roughly 4-year intervals. In these analyses, data through exam 8 in 2005-2008 are included. At each examination visit, the following types of data were collected from each participant: anthropometric measures, urinalysis, blood chemistries, blood pressure, medical history and lifestyle habits. At each visit, subjects were asked to report any diseases or conditions that had occurred since their last visit.

Subjects were included in these analyses if they met the following criteria: (1) had baseline weight and height measures; (2) had follow-up weight measures for at least 10 years for determination of weight change (mean weight change period: 14.3 years), (3) were $45-<70$ years of age at the end of the weight change period, (4) had complete data for metabolic variables of interest (i.e. high-density lipoprotein-cholesterol (HDL-C),

\footnotetext{
${ }^{1}$ Preventive Medicine and Epidemiology, Department of Medicine, Boston University School of Medicine, Boston, MA 02118, USA; ${ }^{2}$ General Internal Medicine, Department of Medicine, Boston University School of Medicine, Boston, MA 02118, USA and ${ }^{3}$ Framingham Heart Study, National Heart, Lung, and Blood Institute, Framingham, MA 01702, USA Correspondence: Lynn L. Moore (IImoore@bu.edu)
}

Received: 15 November 2017 Revised: 11 April 2018 Accepted: 13 April 2018

Published online: 13 June 2018 


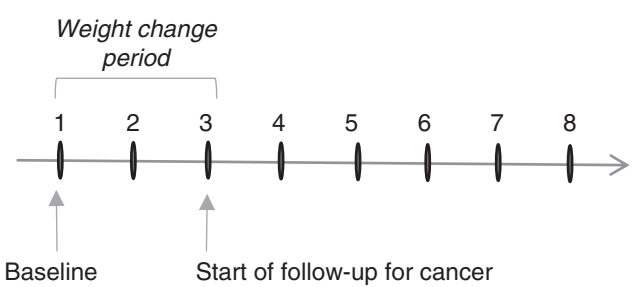

Fig. 1 Timeline for data used in the weight change analyses in the Framingham Offspring Study. The interval between exam 1 and 2 was 8 years, while the interval between exams for all subsequent exams was 4 years. For some subjects, baseline was at exam 2 or 3 (if not in age range at exam 1). In this case, the weight change period and cancer follow-up periods were moved forward

triglycerides, blood glucose and blood pressure) and (5) had complete data for all confounders included in the final models (age, height, physical activity, cigarettes per day, education and alcohol intake). A total of 3850 individuals were included in these analyses.

\section{Exposure measurements}

Height and weight were measured at each visit using a standard beam balance. ${ }^{13}$ The average of all measures of height prior to age 60 years was used in combination with exam-specific weight measures to calculate exam-specific body mass index (BMI). Using a method previously applied in Framingham, subject-specific slopes for weight change were estimated for each subject by regressing weight on age from baseline to the end of the weight change period. ${ }^{14}$ To be included in the weight change analysis, subjects were required to have a minimum of 10 years of followup and three measures of weight. The slopes of weight change were used to classify each subject into one of the following categories: (1) gained $\geq 0.45 \mathrm{~kg} /$ year (1 pound/year), (2) lost $\geq 0.45$ $\mathrm{kg} /$ year or (3) remained weight stable (neither gained nor lost $0.45 \mathrm{~kg}$ or more per year). Since subjects were required to have a minimum of 10 years of follow-up, this means that the weight gain group gained at least $4.5 \mathrm{~kg}$ during follow-up. The weight stable served as referent group for all analyses. Figure 1 shows the timeline for the measurements described.

For the secondary analyses, subjects were classified according to BMI status at baseline and again at the end of the weight change period (10-20 years after baseline) as shown in Fig. 1. Based on our a priori hypothesis, sensitivity analyses and previous evidence that a BMI between 25 and $30 \mathrm{~kg} / \mathrm{m}^{2}$ in men and women would reflect different amounts of true body fat and differing levels of metabolic dysfunction, separate cutoff values were used to define overweight in women and men. ${ }^{15}$ Among women, BMI was dichotomised at each time point as $<25 \mathrm{vs}$. $\geq 25 \mathrm{~kg} / \mathrm{m}^{2}$. Using BMI status at these two time points, change was classified for women as follows: (a) BMI $<25 \mathrm{~kg} / \mathrm{m}^{2}$ (normal weight) at baseline and normal weight at the end of weight change period, (b) overweight at baseline (BMI $\geq 25 \mathrm{~kg} / \mathrm{m}^{2}$ ) but normal weight by the end of weight change period, (c) normal weight at baseline but overweight by the end of the weight change period and (d) overweight at baseline and remained overweight. Since the rates of obesity-related cancer were the same among subjects in the first two categories above and since very few subjects went from being overweight at baseline to normal weight at follow-up (2\% of subjects), these first two groups were combined and used as the referent group for these analyses (called non-overweight middleaged adults). The other two exposure groups will be identified as those who 'became overweight' (during middle age) and those who were 'consistently overweight' (from younger years into middle age). The same approach was used for men, but with BMI classified as $<30 \mathrm{vs}$. $\geq 30 \mathrm{~kg} / \mathrm{m}^{2}$, since this cutoff value for men has been shown to be a more accurate predictor of obesity. ${ }^{15}$
Metabolic dysfunction in these analyses was defined as the presence of two or more of the following risk factors: (a) impaired fasting glucose (IFG) or type 2 diabetes mellitus (T2DM), (b) low HDL-C or elevated triglycerides or taking lipid-lowering medications and (c) high blood pressure (HBP). Prevalent metabolic dysfunction and prevalent IFG or T2DM were crossclassified with weight change to examine potential effect modification by metabolic abnormalities.

In Framingham, IFG and T2DM were diagnosed using the standardised protocols that accounted for uncertain fasting time at exams 1 and 2. T2DM was diagnosed at any exam at which the subject reported using a hypoglycaemia medication (oral or insulin) or if the blood glucose level (fasting or not) was $\geq 200 \mathrm{mg} /$ dl. Subjects with a glucose level between 126 and $200 \mathrm{mg} / \mathrm{dl}$ were diagnosed as having T2DM at that exam if any of the following conditions were met: (a) fasted for $10 \mathrm{~h}$ or more, (b) had a history of diabetes or (c) developed definite diabetes at the next exam without gaining weight ( $7 \%$ or more) between exams. At exams 1 and 2, IFG was defined as a glucose level of $126 \mathrm{mg} / \mathrm{dl}$ or higher without meeting criteria for T2DM. At all subsequent exams, those who fasted for at least $10 \mathrm{~h}$ were considered to have IFG when fasting glucose was $100-125 \mathrm{mg} / \mathrm{dl}$. For some analyses, those with IFG and T2DM were combined to indicate the presence of any glucose dysregulation.

Lipid levels at each exam were derived from blood specimens of subjects fasting at least $12 \mathrm{~h}$ using methodology detailed in the previous studies. $^{16,17}$ Plasma HDL-C concentrations were determined through a heparin-manganese chloride precipitation procedure measured using an AA2 Auto Analyzer (Technicon Instruments Corporation, Tarrytown, NY, USA) ${ }^{18}$ described in the Lipid Research Clinics Program. ${ }^{19}$ The plasma HDL-C concentration was determined by subtracting the precipitating portions of LDL and VLDL. Triglycerides were measured through enzymatic methods previously described. ${ }^{20} \mathrm{HDL}$ and triglyceride data were used starting at exam 3 . A subject was classified as having normal $\mathrm{HDL}$ if $\mathrm{HDL}-\mathrm{C} \geq 40 \mathrm{mg} / \mathrm{dl}$ (men) or $\geq 50 \mathrm{mg} / \mathrm{dl}$ (women) and low $\mathrm{HDL}$ if $\mathrm{HDL}-\mathrm{C}<40 \mathrm{mg} / \mathrm{dl}$ (men) or $<50 \mathrm{mg} / \mathrm{dl}$ (women). A subject was classified as having dyslipidaemia if they took lipid-lowering medication, had an HDL-C $<40 \mathrm{mg} / \mathrm{dl}$ (men), $<50 \mathrm{mg} / \mathrm{dl}$ (women) or had a triglyceride level $\geq 150 \mathrm{mg} / \mathrm{dl}$ at their baseline exam. ${ }^{21}$

Blood pressure was measured twice with the subject in a seated position. ${ }^{13}$ The mean of two measures for systolic blood pressure (SBP) and diastolic blood pressure (DBP) was used to define HBP status according to the modified JNC-7 criteria as follows: use of medication for hypertension; SBP $\geq 160 \mathrm{~mm} \mathrm{Hg}$ or DBP $\geq 95 \mathrm{~mm}$ $\mathrm{Hg}$; or SBP $\geq 140 \mathrm{~mm} \mathrm{Hg}$ or DBP $\geq 90 \mathrm{~mm} \mathrm{Hg}$, where SBP was $\geq 130 \mathrm{~mm} \mathrm{Hg}$ or DBP was $\geq 85 \mathrm{~mm} \mathrm{Hg}$ within the previous two exams.

\section{Cancer outcomes}

Potential cancer cases were first identified through complete medical record review and then subsequently confirmed through pathology, laboratory and/or clinical records. ${ }^{22}$ Cancer diagnosis dates were taken from pathology reports unless diagnosis occurred prior to pathology testing or, in a small number of cases, when pathology results were not available. In the latter case, date of diagnosis was derived from clinical records. ${ }^{23}$ Selfreported cancer diagnoses without pathological or clinical confirmation were not included. Cancer cases were coded using the International Classification of Diseases for Oncology.

Obesity-related cancer outcomes were selected based on previously published studies and included the following: female reproductive (postmenopausal breast, uterine/endometrial and ovarian), colon, rectum, stomach, liver, gallbladder, pancreas, kidney, thyroid, oesophageal adenocarcinoma, leukaemia, nonHodgkin lymphoma and multiple myeloma. ${ }^{1,24}$ Cases of cancer arising from the uterine cervix were excluded due to its 
Table 1. Characteristics according to average yearly weight change

\begin{tabular}{|c|c|c|c|c|c|c|}
\hline & \multicolumn{3}{|l|}{ Men } & \multicolumn{3}{|l|}{ Women } \\
\hline Age (years), mean (s.d.) & $41.1(7.6)$ & $38.5(8.0)$ & $35.9(7.6)$ & $42.7(6.4)$ & $38.3(7.9)$ & $35.6(7.1)$ \\
\hline BMI $\left(\mathrm{kg} / \mathrm{m}^{2}\right)$, mean (s.d.) & $29.2(4.1)$ & $26.7(3.2)$ & $26.4(3.8)$ & $30.2(7.3)$ & $23.6(4.0)$ & $24.2(4.5)$ \\
\hline \multicolumn{7}{|c|}{ Start of follow-up (end of weight change period) } \\
\hline Age (years), mean (s.d.) & $54.2(6.7)$ & $52.6(6.6)$ & $50.7(5.9)$ & $55.7(6.0)$ & $52.5(6.6)$ & $50.5(5.6)$ \\
\hline BMI $\left(\mathrm{kg} / \mathrm{m}^{2}\right)$, mean (s.d.) & $26.1(3.8)$ & $27.0(3.2)$ & $30.4(4.5)$ & $26.4(6.4)$ & $24.3(3.9)$ & $29.4(5.6)$ \\
\hline $\begin{array}{l}\text { Alcohol intake (g/week), } \\
\text { mean (s.d.) }\end{array}$ & $19.0(32.4)$ & $17.9(22.2)$ & $17.0(21.8)$ & $7.3(15.1)$ & $8.5(12.9)$ & $7.2(12.6)$ \\
\hline $\begin{array}{l}\text { Weight change, kg/year, } \\
\text { mean (s.d.) }\end{array}$ & $-0.73(0.25)$ & $0.06(0.23)$ & $0.82(0.37)$ & $-0.78(0.40)$ & $0.12(0.22)$ & $0.93(0.46)$ \\
\hline $\begin{array}{l}\text { Education (>HS), } n \\
\text { (column \%) }\end{array}$ & $77(53.1)$ & $745(63.8)$ & 365 (68.9) & $37(41.1)$ & $623(56.0)$ & $446(55.4)$ \\
\hline T2DM, n (column \%) & $27(18.6)$ & $59(5.1)$ & $32(6.0)$ & $15(16.7)$ & $27(2.4)$ & $30(3.7)$ \\
\hline $\begin{array}{l}\text { Dyslipidemia, } n \\
\text { (column \%) }\end{array}$ & $59(40.7)$ & $597(51.1)$ & $329(62.1)$ & $41(45.6)$ & $387(34.8)$ & $417(51.8)$ \\
\hline HBP, $n$ (column \%) & $59(40.7)$ & $467(40.0)$ & $233(44.0)$ & $47(52.2)$ & 307 (27.6) & $240(29.8)$ \\
\hline
\end{tabular}

association with human papilloma virus. There were a total of 310 obesity-related cancers included in these analyses.

For colorectal cancer, tumours in the proximal and distal colon were included. Proximal colon cancer included cancer in the caecum, ascending colon, hepatic flexure, transverse colon and splenic flexure. Distal colon cancer included cancer in the descending and sigmoid colon. Appendiceal carcinomas were excluded. Female breast cancer excluded tumours in the skin of the breast.

\section{Statistical analyses}

The rates of obesity-related cancer were calculated for each weight change and weight status change exposure category. Person-years of follow-up time were calculated from the end of the weight change period to the first of the following events: occurrence of an obesity-related cancer, loss to follow-up, date of last exam or date of death. Cancer incidence per 1000 personyears was calculated by dividing the number of obesity-related cancers by the total number of person-years in a given exposure category. Cox proportional hazards were used to estimate hazards ratios for the occurrence of the first obesity-related cancer. The proportional hazards assumptions were tested in all models, and no violations of the assumption were found.

To estimate the independent effect of weight change on obesity-related cancer, all analyses controlled for age (years), sex, cigarettes per day, grams of alcohol per week, average adult height (inches), education (dichotomised as some college or more vs. less) and physical activity. A physical activity index was created by summing self-reported hours of moderate and vigorous activity per day with each type of activity being weighted by the oxygen consumption required for that activity. Factors, such as parity, that were not confounders of the relationship between weight change and cancer risk were excluded from the multivariable models.
While time-varying covariates were explored by including changing risk factors such as activity, these risk behaviours were generally stable (thus leading to no changes in the estimated effects). To address concerns about competing risks, we also explored interim development of cardiovascular disease in the models. There was no evidence of bias introduced by competing risks in these analyses.

\section{RESULTS}

Table 1 shows that 145 men and 90 women lost at least one pound per year for at least 10 years; these subjects had a higher mean baseline BMI and were on average slightly older. Those who gained at least a pound per year were slightly younger at baseline. A higher percentage of those who lost weight had T2DM at baseline. The mean weight loss for men in the weight loss category was $0.72 \mathrm{~kg}$ (1.6 pounds)/year, while for women it was $0.77 \mathrm{~kg}$ (1.7 pounds)/year. Mean weight gain (in the weight gain category) was $0.81 \mathrm{~kg}$ (1.8 pounds)/year for men and $0.80 \mathrm{~kg}$ (2.0 pounds)/year for women.

After controlling for confounding by age, height, education level, cigarettes/day, alcohol intake, physical activity, BMI at the start of the weight change period and age at the start of the weight change period, men and women who gained at least a pound per year had a higher risk of obesity-related cancer than those who had stable weight (hazard ratio (HR) 1.32; $95 \%$ confidence interval $(\mathrm{Cl}), 0.88,2.00$ for men; $\mathrm{HR} 1.39 ; 95 \% \mathrm{Cl}$, $1.03,1.87$ for women). There was no effect of weight loss on cancer risk (Table 2 ).

Table 3 explores the independent and combined effects of weight gain and metabolic dysfunction on obesity-related cancers; subjects who lost weight or had stable weight were combined into a single group. Subjects with stable weight or weight loss and 
no metabolic dysfunction (defined as two or more metabolic abnormalities) served as the referent group for all analyses. Weight gain in combination with metabolic dysfunction led to a $77 \%$ increased risk of obesity-related cancer $(95 \% \mathrm{Cl}, 1.21,2.59)$, while weight gain alone led to a $31 \%$ increased risk $(95 \% \mathrm{Cl}, 1.00$, 1.71). Those with stable weight (or who lost weight) who also had two or more metabolic problems had a non-statistically significant $21 \%$ increased risk of obesity-related cancer.

To determine whether T2DM or IFG might be a stronger predictor of cancer risk than metabolic dysfunction as defined by any two or more metabolic abnormalities, we examined the independent and combined effects of T2DM or IFG and weight

\begin{tabular}{|c|c|c|c|c|c|}
\hline Weight change ${ }^{a}$ & $N$ & PY & Cases & I/1000 py & $\mathrm{HR}(95 \% \mathrm{CI})^{\mathrm{b}}$ \\
\hline \multicolumn{6}{|l|}{ All subjects } \\
\hline Weight loss & 235 & 3631 & 20 & 5.51 & $1.05(0.65,1.69)$ \\
\hline Weight stable & 2280 & 35,901 & 173 & 4.82 & 1.00 \\
\hline Weight gain & 1335 & 19,180 & 117 & 6.1 & $1.38(1.09,1.76)$ \\
\hline \multicolumn{6}{|l|}{ Men } \\
\hline Weight loss & 145 & 2210 & 12 & 5.43 & $1.17(0.62,2.18)$ \\
\hline Weight stable & 1168 & 18,274 & 74 & 4.05 & 1.00 \\
\hline Weight gain & 530 & 7568 & 34 & 4.49 & $1.32(0.88,2.00)$ \\
\hline \multicolumn{6}{|l|}{ Women } \\
\hline Weight loss & 90 & 1421 & 8 & 5.63 & $0.87(0.41,1.84)$ \\
\hline Weight stable & 1112 & 17,627 & 99 & 5.62 & 1.00 \\
\hline Weight gain & 805 & 11,613 & 83 & 7.15 & $1.39(1.03,1.87)$ \\
\hline \multicolumn{6}{|c|}{$\begin{array}{l}\mathrm{Cl} \text { confidence interval, } / / 1000 \text { py incidence of cancer cases per } 1000 \text { person- } \\
\text { years, } H R \text { hazards ratio. }{ }^{a} \text { Weight loss = loss of } 0.45 \mathrm{~kg} \text { or more per year, } \\
\text { weight gain = gain of } 0.45 \mathrm{~kg} \text { or more per year, weight stable = loss or gain } \\
\text { of }<0.45 \mathrm{~kg} / \text { year. }{ }^{\mathrm{b}} \mathrm{Adjusted} \text { for sex (for all subjects model), age, average } \\
\text { adult height, education, cigarettes per day, alcohol intake, physical activity, } \\
\text { and BMI at baseline }\end{array}$} \\
\hline
\end{tabular}

gain (Supplemental Table 1). Here, in the absence of weight gain, there was no increased risk of obesity-related cancer associated with prevalent IFG or T2DM. The highest cancer risks were found in both men and women with prevalent IFG or T2DM who had gained more than a pound per year during the weight change period $(\mathrm{HR}, 1.64 ; 95 \% \mathrm{Cl}, 1.17,2.28$ for men and women combined).

Table 4 shows the BMI status change over the weight change exposure period. Men with a BMl of $30 \mathrm{~kg} / \mathrm{m}^{2}$ or higher were considered overweight, while women with a BMI of $25 \mathrm{~kg} / \mathrm{m}^{2}$ or higher were considered overweight. In the first BMI status category, men who were 'not overweight' had a mean BMI of $25.6 \mathrm{~kg} / \mathrm{m}^{2}$ at baseline and a BMI of $26.2 \mathrm{~kg} / \mathrm{m}^{2}$ at the end of the weight change period, reflecting some weight gain but not enough to change their classification status. Women in the same category had a baseline BMI of $21.5 \mathrm{~kg} / \mathrm{m}^{2}$ and a subsequent BMI of $22.4 \mathrm{~kg} / \mathrm{m}^{2}$. Compared with the 'not overweight' group, men who became overweight had a 2.18-fold increased risk of obesityrelated cancer; women who became overweight had a 1.60-fold increased cancer risk. In contrast, both men and women who were already overweight at baseline and remained overweight throughout the weight change period (over an average of 14.3 years) had about a $30 \%$ increased risk of cancer. It is also evident in this table that, despite having a higher cancer risk, those who became overweight had a lower BMI at the end of the weight change period than those who were previously overweight and remained so throughout the exposure period.

The final table (Table 5), which combines male and female subjects, examines whether metabolic dysfunction modifies the effect of individual changes in BMI status. Once again, it is evident that those who became overweight had higher risks of obesityrelated cancer than those who were already overweight at baseline. Subjects with metabolic dysfunction who became overweight had more than twice the risk of obesity-related cancer than those who were not overweight and did not have metabolic dysfunction. Even without metabolic dysfunction, those who became overweight had a $72 \%$ increased risk of cancer $(95 \% \mathrm{Cl}$, $1.26,2.36)$.

Table 3. Risk of obesity-related cancer according to combined effect of weight change and MetDys

\begin{tabular}{|c|c|c|c|c|c|}
\hline Weight change ${ }^{a} /$ MetDys & $N$ & PY & Cases & $\mathrm{l} / 1000$ py & $\mathrm{HR}(95 \% \mathrm{Cl})^{\mathrm{b}}$ \\
\hline \multicolumn{6}{|l|}{ All subjects } \\
\hline Weight loss or weight stable/no MetDys & 2131 & 33,908 & 161 & 4.75 & 1.00 \\
\hline Weight loss or weight stable/MetDys & 384 & 5623 & 32 & 5.69 & $1.21(0.83,1.78)$ \\
\hline Weight gain/MetDys & 295 & 3962 & 32 & 8.08 & $1.77(1.21,2.59)$ \\
\hline Weight gain/no MetDys & 385 & 5681 & 22 & 3.87 & $1.15(0.71,1.87)$ \\
\hline Weight loss or weight stable/MetDys & 266 & 3767 & 20 & 5.31 & $1.25(0.76,2.08)$ \\
\hline Weight gain/MetDys & 145 & 1887 & 12 & 6.36 & $1.85(1.00,3.44)$ \\
\hline \multicolumn{6}{|l|}{ Women } \\
\hline Weight loss or stability/no MetDys & 1084 & 17,192 & 95 & 5.53 & 1.00 \\
\hline
\end{tabular}


Table 4. Risk of obesity-related cancer in men and women according to change in weight status during middle age

\begin{tabular}{|c|c|c|c|c|}
\hline Weight status change & $N$ & Baseline $\mathrm{BMI}^{\mathrm{a}}$ & Follow-up BMI & $\mathrm{HR}(95 \% \mathrm{Cl})^{\mathrm{b}}$ \\
\hline \multicolumn{5}{|l|}{ Men } \\
\hline Did not become overweight ${ }^{c}$ & 1389 & 25.6 & 26.2 & 1.00 \\
\hline Sustained overweight ${ }^{\mathrm{e}}$ & 248 & 32.9 & 34.4 & $1.28(0.76,2.14)$ \\
\hline \multicolumn{5}{|l|}{ Women } \\
\hline Sustained overweight ${ }^{\mathrm{e}}$ & 569 & 29.6 & 32.2 & $1.33(0.94,1.88)$ \\
\hline \multicolumn{5}{|c|}{$\begin{array}{l}\text { BMI body mass index, } \mathrm{Cl} \text { confidence interval, } \mathrm{HR} \text { hazards ratio. }{ }^{\mathrm{a}} \text { Mean } \mathrm{BMI} \text { at baseline and at the end of weight change period (average follow-up of } 14 \text { years) } \\
{ }^{\mathrm{b}} \mathrm{Adjusted} \text { for age, average adult height, education, cigarettes per day, alcohol intake and physical activity. }{ }^{\mathrm{C}} \text { Women with } \mathrm{BMI}<25 \mathrm{~kg} / \mathrm{m}^{2} \text { and men with } \mathrm{BM} \\
<30 \mathrm{~kg} / \mathrm{m}^{2} \text { at baseline who had no change in } \mathrm{BMI} \text { category over } \sim 14 \text {-year weight change period. }{ }^{\mathrm{d}} \text { Women with } \mathrm{BMl}<25 \mathrm{~kg} / \mathrm{m}^{2} \text { at baseline who had } \mathrm{BMI} \geq 25 \\
\mathrm{~kg} / \mathrm{m}^{2} \text { at the end of weight change period; men with } \mathrm{BMI}<30 \mathrm{~kg} / \mathrm{m}^{2} \text { at baseline who developed } \mathrm{BMI} \geq 30 \mathrm{~kg} / \mathrm{m}^{2} \text { at the end of weight change period. }{ }^{\text {eWomen }} \\
\text { with } \mathrm{BMI} \geq 25 \mathrm{~kg} / \mathrm{m}^{2} \text { and men with } \mathrm{BMI} \geq 30 \mathrm{~kg} / \mathrm{m}^{2} \text { at baseline who remained overweight throughout weight change period }\end{array}$} \\
\hline
\end{tabular}

\section{DISCUSSION}

In this prospective study of middle-aged men and women who either gained weight $(\geq 0.45 \mathrm{~kg} / \mathrm{year})$ or became overweight or obese (based on change in BMl status) over an average of about 14 years had an increased risk of obesity-related cancer compared with those who had stable weight. The adverse effect of weight gain on cancer risk was stronger among those who also had metabolic dysfunction. There does appear to be some degree of effect modification of weight gain on cancer risk by prevalent metabolic dysfunction.

To better understand the effect of weight gain apart from the amount and duration of excess weight, BMl status at the beginning and end of the weight gain period was considered. Men and women whose weight gain was such that they became overweight over more than a decade of follow-up had greater risks of obesity-related cancer than those who were already overweight at baseline and remained that way throughout. Further, those who became overweight over the ensuing decade had an excess cancer risk even in the absence of metabolic dysfunction. The adverse effect of weight gain was not explained by having a higher absolute BMI level at the end of follow-up, since those who became overweight actually had a lower mean BMI both at baseline and at the end of the weight change period than those who were persistently overweight.

The cancer-promoting effects of weight gain, particularly at older ages, may be distinct from those of BMI. Cellular ageing is a stress response that may protect against cancer development earlier in life, but that may promote potentially cancerous hyperplasias in middle-aged and older adults. ${ }^{25}$ This process of cellular ageing is pro-inflammatory and associated with the release of cytokines, chemokines, and growth factors which in combination with weight gain, also a pro-inflammatory state, may induce the multi-step cancer process. It has also been shown in randomised controlled trials that intentional weight loss is associated with reductions in C-reactive protein, tumour necrosis factor- $a$, and interleukin- ${ }^{26,27}$ It is possible that the cumulative impact of various pro-inflammatory factors on carcinogenesis may be more evident during times of weight gain than during times of weight stability, even when the individual is already overweight.

Some studies have examined the relation between weight or $\mathrm{BMI}$ change and overall obesity-related cancer risk and our results are consistent with some of these. One such study found that for every $5 \%$ increase in weight from age 25 years to middle-adult years (ages 45-64 years), there were small (3-7\%) increases in risk of obesity-related cancers. ${ }^{8}$ However, for every an increase in BMI of $5 \mathrm{~kg} / \mathrm{m}^{2}$, there was an associated $38 \%$ increased risk of obesity- related cancer. In the Health Professional's Follow-up Study, weight gains of $10-14.9$ and $\geq 15 \mathrm{~kg}$ (vs. $<2.5 \mathrm{~kg}$ ) from age 21 to ages $40-75$ years were associated with 16 and $46 \%$ higher risks, respectively, of obesity-related cancer (colorectal, renal, pancreatic and oesophageal) in men. ${ }^{5}$ An analysis from the WHI found a statistically significant $7 \%$ increased risk of obesity-related cancer over 10 years among overweight subjects. ${ }^{7}$ Most recently, analyses of data from the Nurses' Health Study reported a linear increase in obesity-related cancer associated with increasing amounts of weight gain. ${ }^{9}$

The most common obesity-related cancer among women in our analysis was postmenopausal breast cancer, a cancer that is the most frequently studied obesity-related cancer in general. ${ }^{2-4,28-33}$ Data from the National Institutes of Health-AARP Diet and Health Study found that weight gain during several different periods of life (i.e. young adult years, later reproductive years, postmenopausal years) was associated with increased risks of postmenopausal breast cancer, ${ }^{2}$ while a cohort of Norwegian women found that weight gain during the premenopausal and perimenopausal periods (but not the postmenopausal years) was associated with increased risks of postmenopausal breast cancer. ${ }^{34}$ These results are consistent with our results among women who were in their late 30 s on average at the beginning of the weight change period. Lifetime weight gain among women in the original Framingham cohort was also associated with increased risk of later-onset breast cancer. ${ }^{35}$ Finally, a meta-analysis of weight gain and individual obesity-related cancers found that for every $5 \mathrm{~kg}$ increase in weight there was a statistically significant $11 \%$ increased risk of postmenopausal breast cancer (among non-users of hormone replacement therapy (HRT)), a 13\% increased risk of ovarian cancer and a $39 \%$ increased risk of postmenopausal endometrial cancer. $^{36}$ This same study found a statistically significant $6 \%$ increased risk of colon cancer in men for every $5 \mathrm{~kg}$ gain in weight. Prior studies of weight change and colon cancer risk have shown mixed results, especially in women. ${ }^{6,37-40}$ Finally, another 2015 meta-analysis found an increased risk for endometrial cancer associated with weight gain, regardless of HRT use. ${ }^{41}$

There are a number of important strengths of this study, including the availability of repeated weight measurements rather than self-reported weight, allowing for a more stable and unbiased estimate of weight change. In addition, there was extensive and careful systematic follow-up for the occurrence of cancer among study subjects, minimising the likelihood of both differential and non-differential misclassification of the outcome. The results are also strengthened by the long-term follow-up for cancer occurrence and the detailed measurement of many important potential confounders. A shortcoming in this study is 
Table 5. Risk of obesity-related cancer according to combined category of weight status change and metabolic dysfunction

\begin{tabular}{|c|c|c|c|c|c|c|c|}
\hline Weight status change ${ }^{a} /$ metabolic dysfunction & $N$ & Baseline $\mathrm{BMI}^{\mathrm{a}}$ & Follow-up BMI ${ }^{\mathrm{a}}$ & PY & Cases & $\mathrm{l} / 1000$ py & $\mathrm{HR}(95 \% \mathrm{Cl})^{\mathrm{b}}$ \\
\hline Not overweight/with MetDys & 296 & 25.5 & 26.2 & 4146 & 21 & 5.06 & $1.24(0.78,1.98)$ \\
\hline Became overweight/with MetDys & 124 & 25 & 30.3 & 1677 & 14 & 8.35 & $2.05(1.18,3.55)$ \\
\hline Sustained overweight ${ }^{\mathrm{e}} /$ without MetDys & 558 & 29.9 & 32.2 & 8855 & 52 & 5.87 & $1.21(0.87,1.69)$ \\
\hline
\end{tabular}

$\mathrm{Cl}$ confidence interval, $H R$ hazards ratio, l/1000 py incidence of cancer cases per 1000 person-years, MetDy metabolic dysfunction. ${ }^{\mathrm{a}} \mathrm{Mean} \mathrm{BMI}$ at baseline and at the end of weight change period (average follow-up of 14 years). ${ }^{b}$ Adjusted for age, sex, height, education, cigarettes per day, alcohol intake and physical activity. 'Women with BMI $<25 \mathrm{~kg} / \mathrm{m}^{2}$ and men with $\mathrm{BMI}<30 \mathrm{~kg} / \mathrm{m}^{2}$ at baseline who had no change in BMl category over $\sim 14$-year weight change period. ${ }^{d}$ Women with $\mathrm{BMl}<25 \mathrm{~kg} / \mathrm{m}^{2}$ at baseline who had $\mathrm{BMI} \geq 25 \mathrm{~kg} / \mathrm{m}^{2}$ at the end of weight change period; men with BMl $<30 \mathrm{~kg} / \mathrm{m}^{2}$ at baseline who developed $\mathrm{BMI} \geq 30 \mathrm{~kg} / \mathrm{m}^{2}$ at the end of weight change period. ${ }^{e}$ Women with $\mathrm{BM} \geq 25 \mathrm{~kg} / \mathrm{m}^{2}$ and men with $\mathrm{BMl} \geq 30 \mathrm{~kg} / \mathrm{m}^{2}$ at baseline who remained overweight throughout the weight change period

the limited power in some exposure categories, especially when stratifying by metabolic dysfunction. The absence of data on HRT use and oestrogen receptor status for breast cancers among women is another study limitation.

Previous studies have debated the existence of the 'metabolically healthy obese phenotype'. ${ }^{42-44}$ This raises the question of whether chronic inflammation associated with metabolic dysfunction is separate from the pro-inflammatory effects of fat gain and, additionally, whether individual markers of metabolic health (e.g. $\mathrm{HDL}$, triglycerides, blood pressure, glucose) may function differently as modifiers of the effect of weight gain on cancer risk. In these analyses, individual obesity-related cancers varied in frequency and type between men and women. These analyses combined obesity-related cancers into a single outcome, which could mask the independent effects of weight gain and/or metabolic dysfunction on certain cancers. Despite these limitations, this study demonstrates that weight gain during the middleadult years is an important risk factor for obesity-related cancers, independent of metabolic dysfunction and independent of the level of BMI itself.

\section{ACKNOWLEDGEMENTS}

These data were collected with funding from the National Heart, Lung, and Blood Institute (Framingham Study Contract No. N01-HC-25195)

\section{AUTHOR CONTRIBUTIONS}

S.C. wrote proposal, oversaw analyses, interpreted results, wrote manuscript; M.R.S. created data set, conducted analyses, critically revised manuscript; B.E.K. directed cancer data collection, adjudicated cancer outcomes, provided analytical advice, critically revised manuscript; M.L.B. conducted background research, edited and critically revised manuscript; L.L.M. provided direction for study design and statistical analyses, interpreted results, edited and critically revised manuscript. All authors consented to manuscript submission and publication.

\section{ADDITIONAL INFORMATION}

Supplementary information is available for this paper at https://doi.org/10.1038/ s41416-018-0106-x.

Competing interest: The authors declare no competing interests.

Ethical approval:: These analyses were approved by the Boston Medical Center and Boston University Medical Campus Institutional Review Board.

Note: This work is published under the standard license to publish agreement. After 12 months the work will become freely available and the license terms will switch to a Creative Commons Attribution 4.0 International (CC BY 4.0).

\section{REFERENCES}

1. Renehan, A. G., Tyson, M., Egger, M., Heller, R. F. \& Zwahlen, M. Body-mass index and incidence of cancer: a systematic review and meta-analysis of prospective observational studies. Lancet 371, 569-578 (2008).

2. Ahn, J. et al. Adiposity, adult weight change, and postmenopausal breast cancer risk. Arch. Intern Med. 167, 2091-2102 (2007).

3. Eliassen, A. H., Colditz, G. A., Rosner, B., Willett, W. C. \& Hankinson, S. E. Adult weight change and risk of postmenopausal breast cancer. JAMA 296, 193-201 (2006).

4. Morimoto, L. M. et al. Obesity, body size, and risk of postmenopausal breast cancer: the Women's Health Initiative. Cancer Causes Control 13, 741-751 (2002).

5. De Mutsert, R., Sun, Q., Willett, W. C., Hu, F. B. \& Van Dam, R. M. Overweight in early adulthood, adult weight change, and risk of type 2 diabetes, cardiovascular diseases, and certain cancers in men: a cohort study. Am. J. Epidemiol. 179, 1353-1365 (2014).

6. Schlesinger, S. et al. Body weight gain and risk of colorectal cancer: a systematic review and meta-analysis of observational studies. Obes. Rev. 16, 607-619 (2015).

7. Arnold, M. et al. Duration of adulthood overweight, obesity, and cancer risk in the Women's Health Initiative: a longitudinal study from the United States. PLoS Med. 13, 1-16 (2016).

8. Han, X. et al. Body mass index at early adulthood, subsequent weight change and cancer incidence and mortality. Int. J. Cancer 135, 2900-2909 (2014).

9. Zheng, Y. et al. Associations of weight gain from early to middle adulthood with major health outcomes later in life. JAMA 318, 255-269 (2017).

10. Cowey, S. \& Hardy, R. W. The metabolic syndrome: a high-risk state for cancer? Am. J. Pathol. 169, 1505-1522 (2006).

11. Berger, S. M. et al. Associations between metabolic disorders and risk of cancer in Danish men and women--a nationwide cohort study. BMC Cancer 16, 133 (2016).

12. Kannel, W. B., Feinleib, M., McNamara, P., Garrison, R. \& Castelli, W. An investigation of coronary heart disease in families. The Framingham Offspring Study. Am. J. Epidemiol. 110, 281-290 (1979).

13. Garrison, R. J., Kannel, W. B., Stokes, J. \& Castelli, W. P. Incidence and precursors of hypertension in young adults: the Framingham Offspring Study. Prev. Med. (Baltim.) 16, 235-251 (1987).

14. Moore, L. L. et al. Weight loss in overweight adults and the long-term risk of hypertension the Framingham study. Arch. Intern. Med. 165, 1298-1303 (2005).

15. Romero-Corral, A. et al. Accuracy of body mass index in diagnosing obesity in the adult general population. Int J. Obes. 32, 959-966 (2008).

16. Meigs, J. B. et al. Hyperinsulinemia, hyperglycemia, and impaired hemostasis: the Framingham Offspring Study. JAMA 283, 221-228 (2000).

17. Schaefer, E. J. et al. Elevated remnant-like particle cholesterol and triglyceride levels in diabetic men and women in the Framingham Offspring Study. Diabetes Care 25, 989-994 (2002).

18. Garrison, R. et al. The association of total cholesterol, triglycerides and plasma lipoprotein cholesterol levels in first degree relatives and spouse pairs. Am. J. Epidemiol. 110, 313-321 (1979).

19. National Heart and Lung Institute. Lipid Research Clinics Program. Manual of Laboratory Operations, Lipid Research Clinics Program, Volume 1, Lipid and Lipoprotein Analysis, DHEW Publications No. (NIH) 75-628 (1974). (https://archive. org/details/manualoflaborato00nati).

20. McNamara, J. R. \& Schaefer, E. J. Automated enzymatic standardized lipid analyses for plasma and lipoprotein fractions. Clin. Chim. Acta 166, 1-8 (1987). 
21. Third Report of the National Cholesterol Education Program (NCEP) Expert Panel on Detection, Evaluation, and Treatment of High Blood Cholesterol in Adults (Adult Treatment Panel III) final report. Circulation 106, 3143-3421 (2002).

22. Moore, L. L., Chadid, S., Singer, M. R., Kreger, B. E. \& Denis, G. V. Metabolic health reduces risk of obesity-related cancer in Framingham study adults. Cancer Epidemiol. Biomark. Prev. 23, 2057-2065 (2014).

23. Mainous, A. G., Wells, B. J., Koopman, R. J., Everett, C. J. \& Gill, J. M. Iron lipids, and risk of cancer in the Framingham Offspring Cohort. Am. J. Epidemiol. 161, 1115-1122 (2005).

24. McMillan, D., Sattar, N., Lean, M. \& McCardle, C. Obesity and cancer. BMJ 333, 1109 (2006).

25. Campisi, J. Aging, cellular senescence, and cancer. Annu Rev. Physiol. 75, 685-705 (2013).

26. Byers, T. \& Sedjo, R. Does intentional weight loss reduce cancer risk? Diabetes Obes. Metab. 13, 1063-1072 (2011).

27. Fisher, G. et al. Markers of inflammation and fat distribution following weight loss in African-American and white women. Obesity (Silver Spring) 20, 715-720 (2012).

28. Feigelson, H. S., Jonas, C. R., Teras, L. R., Thun, M. J. \& Calle, E. E. Weight gain, body mass index, hormone replacement therapy, and postmenopausal breast cancer in a large prospective study. Cancer Epidemiol. Biomark. Prev. 13, 220-224 (2004).

29. Huang, Z. et al. Dual effects of weight and weight gain on breast cancer risk. JAMA 278, 1407-1411 (1997).

30. Lahmann, P. H. et al. Long-term weight change and breast cancer risk: the European prospective investigation into cancer and nutrition (EPIC). Br. J. Cancer 93 582-589 (2005).

31. Harvie, M. et al. Association of gain and loss of weight before and after menopause with risk of postmenopausal breast cancer in the lowa women's health study. Cancer Epidemiol. Biomark. Prev. 14, 656-661 (2005).

32. Eng, S. M. et al. Body size changes in relation to postmenopausal breast cancer among women on Long Island, New York. Am. J. Epidemiol. 162, 229-237 (2005).
33. Rosner, B. et al. Weight and weight changes in early adulthood and later breast cancer risk. Int. J. Cancer 140, 2003-2014 (2017).

34. Alsaker, M., Janszky, I., Opdahl, S., Vatten, L. \& Romundstad, P. Weight change in adulthood and risk of postmenopausal breast cancer: the HUNT study of Norway. Br. J. Cancer 109, 1310-1317 (2013).

35. Radimer, K. L. et al. Weight change and the risk of late-onset breast cancer in the original Framingham cohort. Nutr. Cancer 49, 7-13 (2004).

36. Keum, N. et al. Adult weight gain and adiposity-related cancers: a dose-response meta-analysis of prospective observational studies. J. Natl. Cancer Inst. 107, 1-14 (2015).

37. Aleksandrova, K. et al. Adult weight change and risk of colorectal cancer in the European Prospective Investigation into Cancer and Nutrition. Eur. J. Cancer 49, 3526-3536 (2013).

38. Nock, N. L., Thompson, C. L., Tucker, T. C., Berger, N. A. \& Li, L. Associations between obesity and changes in adult $\mathrm{BMI}$ over time and colon cancer risk. Obesity (Silver Spring)16, 1099-1104 (2008).

39. Renehan, A. G. et al. Body mass index at different adult ages, weight change, and colorectal cancer risk in the National Institutes of Health-AARP cohort. Am. J. Epidemiol. 176, 1130-1140 (2012).

40. Bisschop, C. N. S. et al. Weight change later in life and colon and rectal cancer risk in participants in the EPIC-PANACEA study. Am. J. Clin. Nutr. 99, 139-147 (2014).

41. Aune, D. et al. Anthropometric factors and ovarian cancer risk: a systematic review and nonlinear dose-response meta-analysis of prospective studies. Int. J. Cancer 136, 1888-1898 (2015).

42. Kahn, R. Metabolic syndrome: is it a syndrome? Does it matter? Circulation 115, 1806-1810 (2007).

43. Simmons, R. K. et al. The metabolic syndrome: useful concept or clinical tool? Report of a WHO expert consultation. Diabetologia 53, 600-605 (2010).

44. Gale, E. Should we dump the metabolic syndrome? Yes. BMJ 336, 640 (2008).

(n) 